\title{
РЕГИОНАЛЬНЫЙ МОНИТОРИНГ ГОСТИНИЧНЫХ УСЛУГ В СИСТЕМЕ УПРАВЛЕНИЯ КОМПЛЕКСОМ ГОСТЕПРИИМСТВА В ГОРОДЕ И РЕГИОНЕ
}

\author{
H.A. МИХЕЕВА \\ д.социол.н., профессор,
}

Санкт-Петербургский государственный университет сервиса и экономики

\begin{abstract}
Аннотация
Необходимость создания регионального мониторинга гостиничных услуг обусловлена потребностью в научной обоснованности планов и программ дальнейтего развития системь гостеприимства в России и недостаточностью информаџии о состоянии гостиничного сервиса в городах и регионах. $B$ статье раскрывается понятие регионального мониторинга, рассматриваются вопросы применения методов статистики, социологии и маркетинга для изучения сущцествующей инфраструктуры гостиничных услуг, разработки карты регионального мониторинга, создания и постоянного функционирования научно-исследовательского или административного органа регионального мониторинга гостиничных услуг.

Ключевые слова: мониторинг, регион, гостиничный сервис, методы статистики, социологии, маркетинга, карта регионального мониторинга.
\end{abstract}

\begin{abstract}
The need for a regional monitoring of hotel services is due to the need for the scientific validity of plans and programs for the further development of hospitality in Russia and the lack of information on the state of the hotel service in the cities and regions. In the article the concept of regional monitoring , questions of application of statistical methods, sociology and marketing for the study of the existing infrastructure of hotel services, the development of map of regional monitoring, creating and continuing operation of the research or administrative authority of the regional monitoring of services.

Keywords: monitoring, region, hotel service , methods of statistics, sociology , marketing , map of regional monitoring.
\end{abstract}

\section{ВВЕДЕНИЕ}

Сегодня индустрия гостеприимства представляет собой мощнейшую систему хозяйства региона и важную составляющую экономики туризма. На гостиничный бизнес приходится около 6\% мирового валового национального продукта и около 5\% всех налоговых поступлений. Он стимулирует, кроме того, развитие других отраслей: строительства, общественного питания, торговли, сельского хозяйства, производства товаров народного потребления и т.д.

Гостиничный бизнес представляет собой экономический комплекс, развитие которого в большой степени объясняется активизацией мобильности населения многих стран. В условиях 
преодоления экономического кризиса, как считают зарубежные эксперты, оценка роста спроса на гостиничные услуги определяется в $9 \%$ для общего годового прироста отелей первого класса, 13 $\%$ - для среднего класса и от 5 до $10 \%$ - в классе гостиниц с низким тарифом. Гостиничный бизнес создает новые рабочие места и выступает зачастую пионером освоения новых районов и способствует ускоренному развитию национальной экономики. В среднем для обслуживания каждых 10 туристов, проживающих в гостинице, необходимо около 3 рабочих мест непосредственно, и 2 рабочих места, косвенно связанных с обслуживанием. Современный гостиничный бизнес как экономическое явление:

1. имеет индустриальную форму;

2. выступает в виде гостиничного продукта и услуг, которые не могут накапливаться и транспортироваться;

3. выступает как механизм перераспределения национального дохода в пользу стран, специализирующихся в гостиничном бизнесе;

4. является мультипликатором роста национального дохода, занятости и развития местной инфраструктуры и роста уровня жизни местного населения;

5. характеризуется высоким уровнем эффективности и быстрой окупаемостью инвестиций;

6. выступает как эффективное средство охраны природы и культурного наследия, поскольку именно эти элементы составляют основу его ресурсной базы;

7. совместим практически со всеми отраслями хозяйства и видами деятельности человека, поскольку именно их дифференциация и дискретность и создают ту разность потенциалов рекреационной среды, которая вызывает потребности людей к перемене мест и познанию.

\section{РЕЗУЛЬТАТЫ И ИХ ОБСУЖДЕНИЕ}

Для поддержки и управления развитием этой важной отрасли экономики в регионе необходим четкий анализ состояния гостиничного бизнеса по его показателям, включая наличие гостиниц всех разрядов и типов, наличие гостиничных номеров всех разрядов и типов, единовременную вместимость гостиниц ( кровати во всех номерах) и заполняемость (место-дни), наличие разнообразного спектра предоставляемых услуг, наличие рабочих мест всевозможных должностей и квалификации, предприятий питания при гостиницах в целом и по отдельным их видам, отношение постояльцев гостиниц к их услугам и персонала - к условиям труда, выбор стратегии конкуренции.

Изучение и постоянное отслеживание этих и других показателей, динамики их развития и прогнозирования на определенной территории и должно стать целью регионального мониторинга гостиничных услуг. Региональный мониторинг - это система наблюдений на региональном уровне за объектами исследований. Отличие обычного мониторинга от регионального заключается в том, что второй вид мониторинга исполняется исключительно в рамках 
определенного региона [1]. Главная цель регионального мониторинга состоит в создании надежной и объективной основы для выработки обоснованной государственной политики регулирования территориального развития и для определения её приоритетов. Система регионального мониторинга должна стать информационно-аналитической базой для решения следующих задач:

- обоснования целей и приоритетных задач государственной региональной политики в РФ и субъектах Федерации;

- предупреждения кризисных региональных ситуаций и региональных конфликтов;

- оценки результативности деятельности федеральных органов, территориальных органов федеральных министерств и ведомств;

- обоснования мер государственной поддержки отдельных территорий, разработка системы прогнозов социально-экономического развития субъектов Российской Федерации и отдельных территорий;

- подготовки ежегодных государственных докладов о региональной социальноэкономической ситуации и о приоритетных направлениях региональной политики в Российской Федерации.

Для достижения этих задач система регионального мониторинга должна обеспечить учет, сбор, анализ и распространение информации правового, экономического, социального, культурологического характера на уровне федеральных округов, экономических районов, субъектов Российской Федерации и муниципальных образований (города и районы). Предметом регионального мониторинга в данном контексте являются региональные ситуации и региональные проблемы, описываемые количественными и качественными, статическими (одномоментными) или динамическими (за несколько периодов) показателями [2]. Полноценный мониторинг, претендующий на объективное отражение сути и корректную диагностику региональных ситуаций и региональных проблем, должен отвечать двум требованиям. Он должен быть:

a) системным, т.е. независимо от содержания и масштаба мониторинг должен дать характеристику социальных, экономических, правовых и иных аспектов рассматриваемой ситуации или проблемы в их взаимосвязи,

б) структурно полным и логически завершенным. Мониторинг должен включать общеобязательные стадии сбора строго определенной информации, её анализа и оценки (диагностики) региональной ситуации или региональной проблемы.

Очевидно, что все эти требования впрямую относятся и к региональному мониторингу гостиничных услуг.

Под региональным мониторингом гостиничных услуг следует понимать процесс постоянного отслеживания региональных ситуаций и региональных проблем на рынке гостиничного сервиса, описываемых количественными и качественными, статическими (одномоментными) или динамическими (за несколько периодов) показателями и параметрами. 
Показатель - это обобщенная характеристика свойств объекта, процесса или явления, выступающая инструментом, обеспечивающим возможность проверки теоретических положений с помощью эмпирических данных.

Можно выделить всего два вида показателей:

- качественные показатели, фиксирующие наличие или отсутствие у рассматриваемого объекта определенного свойства;

- количественные показатели, фиксирующие меру выраженности или значения развития определенного свойства.

В гостиничном сервисе к количественным показателям отнесем:

1. Количество номеров в гостинице, ед.

2. Единовременную вместимость, койко-мест

3. Численность размещенных лиц, человек

4. Заполняемость - место-дни (иногда - койко-сутки), ед.

5. Коэффициент использования номерного фонда.

Для регионального мониторинга гостиничных услуг в качестве количественных показателей будут выступать:

1. Общее количество гостиниц в регионе.

2. $\quad$ Единовременную вместимость, койко-мест - в регионе.

3. Количество гостиниц в регионе по категориям (например, по звездности).

4. Общее количество гостиничных номеров в регионе.

5. Количество гостиничных номеров в регионе по категориям (например, номера люкс, апартаменты и т.д.).

6. Коэффициент использования номерного фонда в регионе.

7. Общее число работников гостиниц в регионе.

8. Число работников гостиниц в регионе по категориям (например, менеджеров, горничных, администраторов, портье, поваров и т.д.).

9. редняя оплата труда работников гостиниц и т.д.

Возможны и другие показатели, которые отражены в составленной автором Kapme регионального мониторинга гостиничных услуг. К качественным показателям гостиничного сервиса следует, в первую очередь, отнести наличие дополнительных услуг - как в отдельных гостиницах, так и в гостиничном комплексе всего региона. Они также перечислены в Карте регионального мониторинга гостиничных услуг. Звездность отеля и его название, используемые системы бронирования гостиничных услуг и средства рекламы тоже будут его качественными показателями. Для расчета относительных показателей, например, коэффициента использования место-дней, показателя средней продолжительности пребывания в гостинице, эффективности деятельности гостиницы (или всего комплекса гостиниц), показателя динамики рынка гостиничных услуг используются различные общепринятые в российской системе государственной и ведомственной статистической отчетности формулы [3]. 
Идентификаторами и параметрами в гостиничном сервисе следует признать те квалификационные требования, которые зафиксированы в стандартах деятельности, т.е. в «Системе классификации гостиниц и других средств размещения», в частности, в Требованиях к средствам размещения и номерам, которые приведены в Приложениях к данному документу [4].

Анализ положения дел показывает, что в России, несмотря на то, что единая система показателей для количественной и качественной оценки в гостиничном сервисе уже сложилась, тем не менее, задача сведения всех показателей и анализа динамики его развития в масштабе региона пока еще полностью не решена. Об это свидетельствуют и статистические данные, которые ежегодно публикуются в Российском статистическом ежегоднике в виде только двух таблиц [5]:

\section{ГОСТИНИЦЫ И АНАЛОГИЧНЫЕ СРЕДСТВА РАЗМЕЩЕНИЯ1)}

\begin{tabular}{l|l|l|l|l|l}
\hline Годы & \multicolumn{2}{l}{$\begin{array}{l}\text { Число } \\
\text { организаций }\end{array}$} & $\begin{array}{l}\text { Их } \\
\text { единовременная } \\
\text { вместимость, } \\
\text { тыс. мест }\end{array}$ & $\begin{array}{l}\text { Годы } \\
\text { организаций }\end{array}$ & $\begin{array}{l}\text { Их } \\
\text { единовременная } \\
\text { вместимость, } \\
\text { тыс. мест }\end{array}$ \\
\hline 1970 & 3549 & 259,7 & 2003 & 3915 & 350,0 \\
1980 & 4737 & 332,9 & 2004 & 4041 & 344,4 \\
1990 & 4686 & 434,8 & 2005 & 4812 & 404,4 \\
1995 & 5504 & 426,1 & 2006 & 5375 & 429,2 \\
2000 & 4182 & 346,1 & 2007 & 5917 & 447,1 \\
2001 & 4120 & 338,4 & 2008 & 6774 & 498,4 \\
2002 & 3872 & 343,3 & 2009 & 7410 & 497,3 \\
\hline
\end{tabular}

1) До 1995 г. данные приведены без учета гостиниц, находившихся на балансе колхозов и совхозов. С 2005 г. данные представлены с учетом физических лиц, осуществляющих предпринимательскую деятельность без образования юридического лица (индивидуальных предпринимателей). 


\section{ЧИСЛЕННОСТЬ ЛИЦ, РАЗМЕЩЕННЫХ В ГОСТИНИЦАХ, САНАТОРНО-КУРОРТНЫХ ОРГАНИЗАЦИЯХ И ОРГАНИЗАЦИЯХ ОТДЫХА (тыс.чел.)}

\begin{tabular}{|c|c|c|c|c|c|c|c|c|c|c|c|c|c|c|c|}
\hline & \multirow{3}{*}{\multicolumn{3}{|c|}{$\begin{array}{c}\text { Численность } \\
\text { размещенных } \\
\text { лиц - всего }\end{array}$}} & \multicolumn{12}{|c|}{ в том числе } \\
\hline & & & & \multicolumn{6}{|c|}{ граждан России } & \multicolumn{6}{|c|}{ иностранных граждан } \\
\hline & & & & \multicolumn{3}{|c|}{ всего } & \multicolumn{3}{|c|}{ из них детей } & \multicolumn{3}{|c|}{$\begin{array}{c}\text { стран дальнего } \\
\text { зарубежья }\end{array}$} & \multicolumn{3}{|c|}{ стран СНГ } \\
\hline & 2000 & 2005 & $2009^{1)}$ & 2000 & 2005 & $2009^{1)}$ & 2000 & 2005 & 2009 & 2000 & 2005 & 2009 & 2000 & 2005 & $2009^{1)}$ \\
\hline Всего & 25073,4 & 28410,9 & 27972,2 & 22001 & 24810,1 & 24916,8 & 2458,3 & 2669,2 & 2510,0 & 1844,1 & 2778,7 & 2377,8 & 1228,3 & 822,1 & 677,6 \\
\hline \multicolumn{16}{|l|}{ в том числе: } \\
\hline $\begin{array}{c}\text { гостиницы и аналогичные } \\
\text { средства размещения }\end{array}$ & 16559,3 & 18546,8 & 18545,7 & 13607 & 15046,9 & 15586,2 & 359,9 & 456,4 & 526,5 & $\begin{array}{c}1787 \\
9\end{array}$ & 2725,6 & 2347,6 & 1164,4 & 774,3 & 611,9 \\
\hline $\begin{array}{c}\text { санаторно-курортные } \\
\text { организации и организации } \\
\text { отдыха - всего }\end{array}$ & 8514,1 & 9864,1 & 9426,5 & 8394,0 & 9763,2 & 9330,6 & 2098,4 & 2212,8 & 1983,6 & 56,2 & 53,1 & 30,2 & 63,9 & 47,8 & 65,8 \\
\hline \multicolumn{16}{|l|}{ из них: } \\
\hline $\begin{array}{c}\text { санаторно-курортные } \\
\text { организации }\end{array}$ & 4583,7 & 5941,2 & 5774,5 & 4524,3 & 5882,8 & 5715,6 & 1197,9 & 1585,2 & 1479,6 & 20,6 & 21,4 & 10,0 & 38,8 & 36,9 & 48,9 \\
\hline организации отдыха & 3345,8 & 3411,0 & 3232,6 & 3305,2 & 3397,6 & 3220,0 & 763,7 & 537,6 & 454,2 & 22,2 & 5,8 & 5,4 & 18,4 & 7,6 & 7,2 \\
\hline туристские базы & 584,6 & 313,6 & 250,0 & 564,5 & 310,6 & 246,8 & 136,8 & 71,6 & 37,1 & 13,4 & 1,7 & 2,0 & 6,7 & 1,3 & 1,1 \\
\hline
\end{tabular}

Без учета микропредприятий. Численность размещенных лиц с учетом микропредприятий составила: всего 31690,3 тыс. человек, в том числе в гостиницах и аналогичных средствах размещения 21174,5 тыс. человек. 
И здесь большое значение приобретает предмет регионального мониторинга - совокупность показателей всего комплекса гостиничных услуг. Основными методами исследования в региональном мониторинге должны стать методы статистики, социологии, маркетинга.

Владение этими методами дает возможность исследователям, а возможно и студентам вузов разных специальностей принимать активное участие в организации регионального мониторинга гостиничных услуг и бизнеса - как в пределах небольших городов, так и районов таких больших городов, как Москва или Санкт-Петербург. Результаты проведенных исследований могут быть использованы при разработке региональных или городских программ и планов развития туризма и гостиничного комплекса. Основным средством обучения и проведения исследования может стать карта регионального мониторинга, в которой сосредоточены показатели по нескольким разделам, а именно:

- общая статистика по гостиницам,

- общая статистика по гостиничным услугам,

- общая статистика по ценам,

- показатели эффективности деятельности,

- статистика по персоналу,

- статистика по доходам и расходам гостиниц,

- используемые системы on-line бронирования,

- анализ тенденций при наименовании гостиниц и их ресторанов (аномастика), их размещению,

- используемые средства рекламы гостиниц в регионе.

Создание подобной карты позволит сохранить преемственность в методологии и методике постоянных исследований, даст возможность для сопоставимости результатов на всем протяжении организации регионального мониторинга гостиничных услуг, создании условий для определения векторов дальнейшего развития гостиничного бизнеса в С.-Петербурге или других городах.

Кроме того, может быть составлена и конкурентная карта рынка гостиничного сервиса. Построению конкурентной карты рынка предшествует расчет для каждого участника рынка таких показателей, как:

1. Динамика рынка.

2. Интенсивность конкуренции по динамике рынка.

3. Рентабельность рынка.

4. Интенсивность конкуренции по рентабельности.

5. Рыночная доля фирмы.

6. Средняя рыночная доля.

7. Интенсивность конкуренции по вариации рыночных долей.

8. Обобщенная характеристика интенсивности конкуренции.

9. Степень монополизации рынка. 
Для определения динамики рынка рассчитывается показатель динамики рынка (Tm) в конце анализируемого и базисного периодов $\left(\mathrm{V}^{\wedge} \mathrm{m} \mathrm{u} \mathrm{Vm}\right)$ и длительность периода $(\mathrm{t})$ :

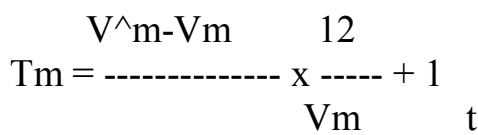

Примем: $\mathrm{Tm}=1,363907$

Если $\mathrm{Tm}>1.4$, то рынок находится в состоянии ускоренного роста, при изменении Tm от 1.4 до 0.7 рынок проходит состояние позиционного роста, стагнации и сворачивания, если $\mathrm{Tm}<0.7$, то ожидается кризис рынка.

В данном случае рынок гостиничного сервиса проходит состояние позиционного роста. С учетом этого положения на конкурентной карте рынка выбираются соответствующие элементы стратегии конкуренции:

- Поиск незанятой ниши со слабой конкуренцией.

- Приспособление к выбранному целевому рынку.

- Создание идеальной услуги.

- Поглощение мелких конкурентов.

- Создание отличительного имиджа.

- Анализ и сокращение издержек.

- Учет ценообразования конкурентов.

- Инновации, снижающие издержки.

- Увеличение продаж услуг старым клиентам.

- Поиск конкурентов - кандидатов на вывод с рынка.

- Выход на внешние рынки для привлечения ресурсов и продажи услуг [6].

Составление обеих предложенных технологических карт станет итоговым результатом проведения мониторинга на рынке гостиничного сервиса в конкретном регионе.

\section{ВЫВОДЫ}

Становится очевидным, что для подобной организации регионального мониторинга необходимо создание и постоянное функционирование научно-исследовательского подразделения регионального мониторинга гостиничных услуг в административном органе, например в С.Петербурге, а возможно, и в его районах. Этот орган может быть создан в недрах Комитета по развитию туризма Администрации города или в администрациях районов города. Он может быть организован и при Законодательном собрании С.-Петербурга, например, в комиссии по городскому хозяйству, градостроительству и земельным вопросам.

На наш взгляд, при определенной поддержке администрации города или районов, этот вопрос может быть доверен и независимым общественным организациям. Подобная работа может 
осуществляться в любых регионах, властные органы которых заинтересованы в развитии туризма и, соответственно, сферы гостиничного хозяйства.

\section{ЛИТЕРАТУРА}

1. Михеева, Н.А. Региональный мониторинг гостиничных услуг и прогнозирование / Н.А. Михеева. - СПб: Изд. Троицкий мост, 2013.- С. 27.

2. Михеева, Н.А. Региональный мониторинг гостиничных услуг и прогнозирование / Н.А. Михеева. - СПб: Изд. Троицкий мост, 2013.- С. 28.

3. Об утверждении статистического инструментария для организации федерального статистического наблюдения за деятельностью, осуществляемой в сфере услуг и туризма, а также за правонарушениями в сфере экономики: Приказ Росстата (в ред. Приказа Росстата от 06.09.2010 $\mathrm{N}$ 306) [Электронный pecypc]. URL http://base.consultant.ru/cons/cgi/online.cgi?req=doc (дата обращения 23.08.2013).

4. Система классификации гостиниц и других средств размещения - утверждена приказом Минкультуры России от 3 декабря 2012 г. N 1488 "Об утверждении порядка классификации объектов туристской индустрии, включающих гостиницы и иные средства размещения, горнолыжные трассы и пляжи, осуществляемой аккредитованными организациями". (Зарегистрировано в Минюсте России 15 мая 2013 г. N 28400). [Электронный ресурс]. URL http://www. Consultant.ru〉law/hotdocs/link/?id=24463 (дата обращения 23.08.2013).

5. Российский статистический ежегодник. 2010: Стат.сб./. - М.: Росстат 2010. - С.303

6. Зевеке, M.A. Построение конкурентной карты рынка. - [Электронный ресурс]. URL http://yandex.ru/yandsearch?text=конкурентная карта, subcontract.ru (дата обращения 23.08.2013). 